\title{
Feasibility of Selective Neck Irradiation with Lower Elective Radiation Dose in Treating Nasopharynx Cancer Patients
}

\author{
Won Kyung Cho, MD ${ }^{1}$ \\ Dongryul Oh, MD, PhD' \\ Eonju Lee, $\mathrm{MD}^{2}$ \\ Tae Gyu Kim, MD2 \\ Hyebin Lee, $\mathrm{MD}^{3}$ \\ Heerim Nam, MD, PhD ${ }^{3}$ \\ Jae Myoung Noh, MD, PhD' \\ Yong Chan Ahn, MD, PhD'
}

${ }^{1}$ Department of Radiation Oncology, Samsung Medical Center, Sungkyunkwan University School of Medicine, Seoul, ${ }^{2}$ Department of Radiation Oncology, Samsung Changwon Hospital, Sungkyunkwan University School of Medicine, Changwon, ${ }^{3}$ Department of Radiation Oncology, Kangbuk Samsung Hospital, Sungkyunkwan

University School of Medicine, Seoul, Korea

\section{Correspondence: Yong Chan Ahn, MD, PhD}

Department of Radiation Oncology,

Samsung Medical Center, Sungkyunkwan

University School of Medicine, 81 Irwon-ro,

Gangnam-gu, Seoul 06351, Korea

Tel: 82-2-3410-2612

Fax: 82-2-3410-2619

E-mail: ahnyc@skku.edu

Received April 23, 2018

Accepted July 16, 2018

Published Online July 18, 2018

*Won Kyung Cho and Dongryul Oh contributed equally to this work.

\begin{abstract}
Purpose
This study aimed to report the clinical outcomes following selective neck irradiation (SNI) with lower elective radiation therapy (RT) dose in treating nasopharyngeal cancer (NPC) patients.
\end{abstract}

\section{Materials and Methods}

A total of 347 NPC patients received definitive RT according to our SNI policy and were retrospectively analyzed. The clinical target volumes (CTVs) were subdivided into CTV at high risk (CTV-HR) and CTV at low risk (CTV-LR). The typical doses to gross tumor volume (GTV), CTV-HR, and CTV-LR were 68.4-70.0 Gy, 54.0-60.0 Gy, and 36.0 Gy.

\section{Results}

With the median follow-up of 68.1 months (range, 2.3 to 197.1 months), the 5-year rates of loco-regional control and progression-free survival in all the patients were $85.0 \%$ and $70.8 \%$, respectively. Thirty patients developed regional failure and the regional control rates at 3 and 5 years were $92.6 \%$ and $91.4 \%$, respectively. The sites of regional failure in relation to the target volume were exclusively inside GTV/CTV-HR in 20, inside and outside GTV/CTV$\mathrm{HR}$ in three, and exclusively outside GTV/CTV-HR in seven, which were 5.7\%, 0.9\%, and $2.0 \%$ of total patients, respectively.

\section{Conclusion}

The clinical outcomes by the current SNI policy were feasible and comparable to those following classic elective nodal irradiation policy.

\section{Key words}

Nasopharyngeal carcinoma, Lymphatic irradiation, Radiotherapy

\section{Introduction}

Radiation therapy (RT) has long been the mainstay treatment for the patients with non-metastatic nasopharynx cancer (NPC), which can lead to $62 \%-80 \%$ of 5 -year overall survival (OS) rate [1]. Considering relatively younger median age of NPC patients (45-50 years) than other head and neck cancers [2], higher level of attention needs to be paid to the quality of life following RT. Xerostomia, altered taste, and dysphagia with mucositis are the most common acute adverse effects during and following RT, which not only bother the patients with pain, but also often interrupt the planned RT course. Chronic xerostomia and altered taste often restrict the patients' capability of speech and swallowing, which often limit their social interactions. 
NPC is associated with lymph node (LN) metastasis frequently $(60 \%-90 \%)$ at time of diagnosis [3]. LN metastasis is usually predictable by virtue of orderly spread pattern and skip metastasis is rare. Nevertheless, bilateral entire neck irradiation used to be typically recommended in RT for NPC patients. This was based on the classic reports on lymphatic failure rates following no elective nodal irradiation (ENI) $(40 \%)$ and partial neck irradiation $(12 \%)$ in most non-NPC head and neck cancer patients $[4,5]$. In the earlier days, when the quality of diagnostic imaging was not satisfactory, discrimination between metastatic and normal LNs was not an easy task. Furthermore, reduced ENI volume did not make big difference in normal organ sparing over entire neck irradiation when the advanced RT techniques such as 3-dimensional conformal RT (3DCRT) and intensity modulated RT (IMRT) were not available. Instead, reduced ENI volume was not widely accepted in fear of missing probable metastatic LNs. However, the refinement of diagnostic imaging modalities and the technical advances in RT have enabled the delivery of selective neck irradiation (SNI) and consequent saving of more surrounding normal organs from high dose radiation. Based on these, tailored lymphatic target volume delineation has recently become popular.

Our institution has employed the SNI policy with lower radiation dose in treating the NPC patients for longer than two decades, and the current study is to report our experiences of the clinical outcomes and toxicities.

\section{Materials and Methods}

\section{Patients}

After approval by the institutional review board, 347 patients who received definitive RT for newly diagnosed non-metastatic NPC from January 2001 to December 2015 were retrospectively reviewed. All patients underwent thorough physical examination, histopathologic confirmation, and computed tomography (CT) scan of the head and neck region. Magnetic resonance imaging was done in 108 patients (31.1\%), in whom the skull base and / or intracranial invasion was suspected. Systemic staging work-up's during the early study period included whole body bone scintigraphy and abdominal ultrasonography in 54 patients (15.6\%), which were later replaced by whole-body 5-fluorodeoxyglucose positron emission tomography and computed tomography (FDG PET-CT) in 293 (84.4\%). Clinical T-stage (cT) and clinical $\mathrm{N}$-stage $(\mathrm{cN})$ categories were allocated according to the seventh edition of the American Joint Committee on Cancer (AJCC) Cancer Staging Manual [6].

\section{Target volume delineation}

All the patients underwent CT simulation. The delineation of the gross tumor volume (GTV) of the primary tumor and LN was done with reference to all the clinically available information including physical examination and imaging

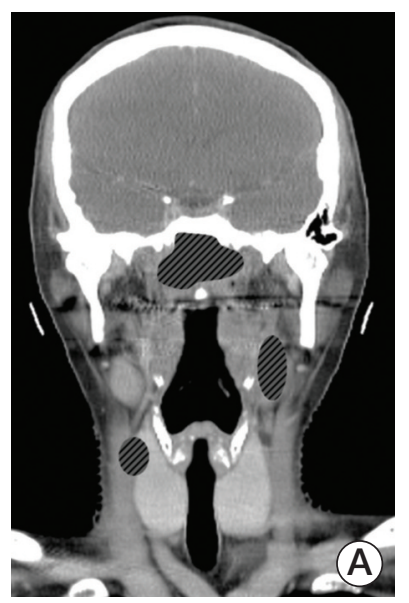

GTV: $66-72 \mathrm{~Gy}$

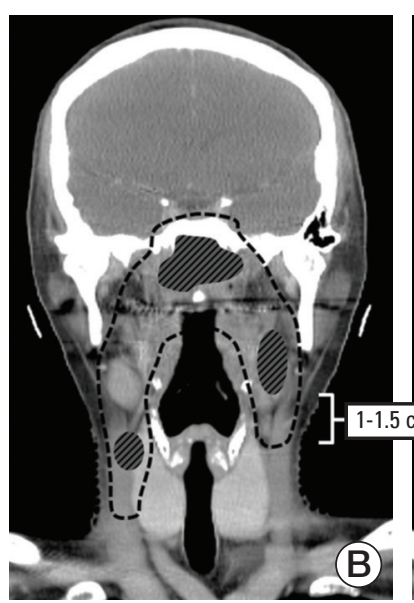

CTV-HR: $54-60 \mathrm{~Gy}$

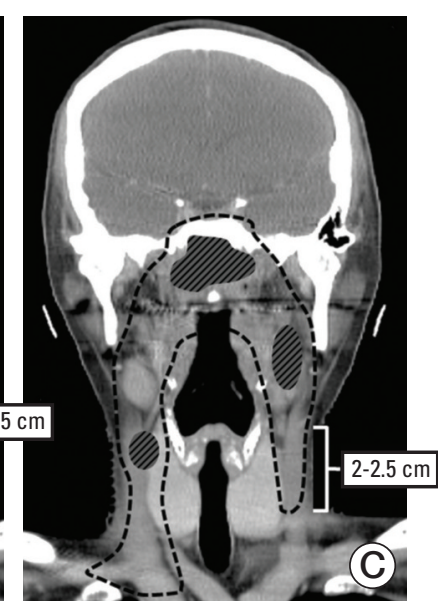

CTV-LR: $36 \mathrm{~Gy}$

Fig. 1. The policy of selective neck irradiation with differential radiation dose plan employed in the current study is illustrated: (A) 66-72 Gy to gross tumor volume (GTV) of primary tumor and metastatic lymph nodes; (B) 54-60 Gy to clinical target volume at high risk (CTV-HR) that included 1.0-1.5 cm margin to nodal GTV; and (C) 36 Gy to clinical target volume at low risk (CTV-LR) that included $2-2.5 \mathrm{~cm}$ distal margin from CTV-HR. 
studies. The diagnosis of metastatic LNs was based either on cyto-histologic confirmation or on more than one of the following radiologic criteria: short axis $\geq 1 \mathrm{~cm}$ (cervical LN) or $\geq 6 \mathrm{~mm}$ (retropharyngeal LN); findings of contrast enhancement, round shape, central nodal necrosis, and/or irregular margin with infiltration to the surrounding structure; and evident FDG uptake regardless of the LN size $[7,8]$. The clinical target volume (CTV) of the primary tumor was delineated by adding 3-5 $\mathrm{mm}$ margins in all directions from GTV of the primary tumor and included the sphenoid sinus, posterior part of nasal cavity and maxillary sinus, and skull base in case of skull base invasion. The lymphatic CTVs were divided into two components: CTV at high risk (CTV-HR) was to encompass the immediately adjacent lymphatic levels to the nodal GTV with $1.0-1.5 \mathrm{~cm}$ margins; and CTV at low risk (CTV-LR) was to include addition 2.0-2.5 cm distal lymphatics from CTV-HR (Fig. 1). All CTVs were edited considering the normal anatomic barriers of the surrounding structures. The planning target volume was generated by adding $3 \mathrm{~mm}$ margin to CTV.

\section{Treatment}

The majority of patients ( $\mathrm{n}=289,83.3 \%$ ) were treated by RT combined with chemotherapy, while RT alone was delivered to 58 patients $(16.7 \%)$, who either had cT1-2N0 disease or medical comorbidities contraindicating chemotherapy (Table 1). Concurrent chemoradiation therapy alone was delivered to 188 patients $(54.2 \%)$. Neoadjuvant and adjuvant chemotherapy before or following RT were delivered to $12(3.5 \%)$ and 90 patients $(25.9 \%)$, respectively, both of which were given mainly during the early study period.

\section{RT techniques and schedules}

During the early part of the current study, 3DCRT was the main technique applied to 152 patients $(43.8 \%)$. By serial shrinking and adaptive re-plans, twice during the course, the typical doses delivered to GTV, CTV-HR, and CTV-LR were 70.0 Gy, 54.0 Gy, and 36.0 Gy over 7 weeks by daily $1.8 \mathrm{~Gy}$ or 2.0 Gy per fraction, respectively. During the later part, when the Korean Health Insurance Policy began to cover the IMRT cost, IMRT by helical tomotherapy was mainly used to treat 195 patients (56.2\%). The simultaneous integrated boost and adaptive re-plan were employed when using IMRT, and the typical doses to GTV, CTV-HR, and CTV-LR were $68.4 \mathrm{~Gy}, 60.0 \mathrm{~Gy}$, and 36.0 Gy over 6 weeks, respectively. The typical fractional dose to GTV and CTV were 2.2 Gy and 2.0 Gy during the first 18 fractions and 2.4 Gy and 2.0 Gy during the remaining 12 fractions.
Table 1. Patients' characteristics

\begin{tabular}{|c|c|}
\hline Characteristic & No. $(\%)(n=347)$ \\
\hline Age, median (range, yr) & $51(16-86)$ \\
\hline \multicolumn{2}{|l|}{ Sex } \\
\hline Male & $267(76.9)$ \\
\hline Female & $80(23.1)$ \\
\hline \multicolumn{2}{|l|}{ Performance status } \\
\hline ECOG 0-1 & $336(96.8)$ \\
\hline ECOG 2 & $11(3.2)$ \\
\hline \multicolumn{2}{|l|}{ Histologic type } \\
\hline Keratinizing squamous cell carcinoma & $56(17.0)$ \\
\hline $\begin{array}{l}\text { Non-keratinizing carcinoma, } \\
\text { differentiated type }\end{array}$ & $67(20.4)$ \\
\hline Undifferentiated carcinoma & $197(59.9)$ \\
\hline Unclassified & $9(2.7)$ \\
\hline \multicolumn{2}{|l|}{ Imaging studies } \\
\hline $\mathrm{CT}$ & $3(0.9)$ \\
\hline CT, MRI & $51(14.7)$ \\
\hline CT, FDG-PET & $236(68.0)$ \\
\hline CT, MRI, FDG-PET & $57(16.4)$ \\
\hline \multicolumn{2}{|l|}{ Clinical T category } \\
\hline cT1 & $157(45.2)$ \\
\hline cT2 & $45(13.0)$ \\
\hline cT3 & $80(23.1)$ \\
\hline cT4 & $65(18.7)$ \\
\hline \multicolumn{2}{|l|}{ Clinical N category } \\
\hline $\mathrm{cN} 0$ & $50(14.4)$ \\
\hline $\mathrm{cN} 1$ & $97(28.0)$ \\
\hline $\mathrm{cN} 2$ & $148(42.7)$ \\
\hline $\mathrm{cN} 3$ & $52(15.0)$ \\
\hline \multicolumn{2}{|l|}{ Treatment } \\
\hline RT alone & $58(16.7)$ \\
\hline $\mathrm{NAC}+\mathrm{RT}$ & $1(0.3)$ \\
\hline CCRT alone & $188(54.2)$ \\
\hline $\mathrm{NAC}+\mathrm{CCRT}$ & $10(2.9)$ \\
\hline $\mathrm{CCRT}+\mathrm{AC}$ & $89(25.6)$ \\
\hline $\mathrm{NAC}+\mathrm{CCRT}+\mathrm{AC}$ & $1(0.3)$ \\
\hline \multicolumn{2}{|l|}{ RT technique } \\
\hline 3D-CRT & $152(43.8)$ \\
\hline IMRT & $195(56.2)$ \\
\hline
\end{tabular}

ECOG, Eastern Cooperative Oncology Group; CT, computed tomography; MRI, magnetic resonance imaging; FDG, 5-fluorodeoxyglucose; PET, positron emission tomography; RT, radiation therapy; NAC, neoadjuvant chemotherapy; CCRT, concurrent chemoradiotherapy; AC, adjuvant chemotherapy; 3D-CRT, 3 dimensional conformal RT; IMRT, intensity-modulated RT. 


\section{Follow-up evaluation and statistical analysis}

The first clinical evaluation was done with CT scan taken in 1 month of RT completion, and the second evaluation was done with PET-CT in 3 months of the first evaluation. The subsequent follow-up evaluations were scheduled at every 3-4 months' interval during the first 2 years, at every 6 months' interval during the third year, and then annually thereafter. Loco-regional failure was defined as the reappearance or new lesion development at the primary site and/or regional lymphatics. The durations of loco-regional control (LRC), progression-free survival (PFS), and OS were calculated from the date of RT start till the date of the event or the last follow-up. The rates of LRC, PFS, and OS were calculated using the Kaplan-Meier methods. All the analyses were conducted using the SPSS Statistics ver. 20 (IBM Corp., Armonk, NY).

\section{Ethical statement}

The study was approved by the Institutional Review Board of Samsung Medical Center (IRB No. 2011-11-105-002) and performed in accordance with the principles of the Declaration of Helsinki. The informed consent was waived.

\section{Results}

\section{Patients' characteristics}

The patients' characteristics are summarized in Table 1. The median age of all patients was 51 years (range, 16 to 86 years), and 267 patients (76.9\%) were male. The most common histologic type was undifferentiated carcinoma in 197 patients $(59.9 \%)$, followed by non-keratinizing carcinoma, differentiated type in $67(20.4 \%)$, keratinizing squamous cell carcinoma in $56(17.0 \%)$, and unclassified in nine $(2.7 \%)$, respectively. cT categories were cT1 in 157 patients $(45.2 \%)$, cT2 in $45(13.0 \%)$, cT3 in $80(23.1 \%)$, and cT4 in $65(18.7 \%)$, respectively. cN categories were $\mathrm{cN} 0$ in 50 patients $(14.4 \%)$, cN1 in 97 (28.0\%), cN2 in 148 (42.7\%), and cN3 in 52 (15.0\%), respectively.

\section{Clinical outcomes and patterns of first failure}

The median follow-up duration was 68.1 months (range, 2.3 to 197.1 months), during which 100 patients (28.8\%) developed disease progression and 83 (23.9\%) died, respectively. The 5-year rates of LRC, PFS, and OS were $85.0 \%$, $70.8 \%$, and $81.1 \%$, respectively. Distant metastasis was the

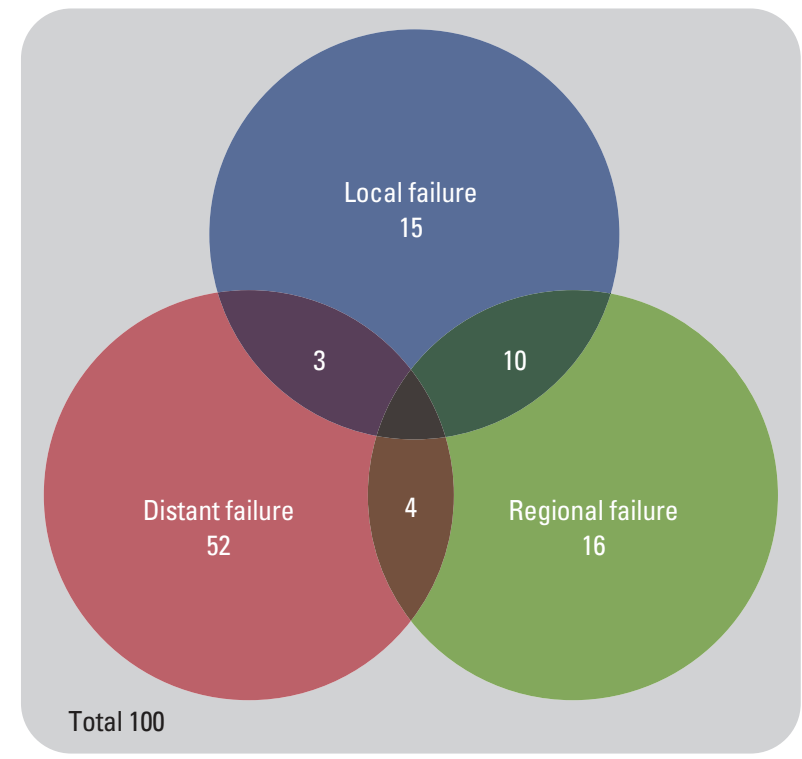

Fig. 2. Patterns of failure in 100 patients.

most common component observed in 59 patients $(17.1 \%)$, followed by components of regional and local failures in 30 $(8.7 \%)$ and $28(8.1 \%)$, respectively (Fig. 2). The most common site of distant metastasis was the lung observed in 23 patients, followed by the bone in 13 , and the liver in six, respectively.

\section{Location of regional failure and salvage treatment}

The sites of regional failure in 30 patients were classified in relation to the target volumes: failure exclusively within CTV-HR in 20 (5.7\%); failure synchronously inside and outside CTV-HR in three (0.9\%); and failure exclusively outside CTV-HR in seven (2.0\%), respectively (Fig. 3). Among seven patients who developed exclusively outside CTV-HR failure, four $(1.1 \%)$ developed exclusively inside CTV-LR failure, one $(0.3 \%)$ did synchronous inside and outside CTV-LR failure, and two $(0.6 \%)$ did exclusively outside CTV-LR failure, respectively. Salvage treatment was attempted in four patients, all of whom were successfully salvaged, while three (no treatment in two and palliative systemic chemotherapy in one) died of disease. The 5-year regional control rates of the patients with $\mathrm{cN} 0, \mathrm{cN} 1, \mathrm{cN} 2$, and $\mathrm{cN} 3$ disease were $94.0 \%$, $85.3 \%, 94.2 \%$, and $95.6 \%$, respectively.

\section{Toxicities}

Table 2 summarizes RT-related toxicity profiles. Grade 3 or higher acute toxicities developed in 44 patients (12.7\%) and mucositis $(\mathrm{n}=19,5.5 \%)$ and nausea/vomiting $(\mathrm{n}=19$, $5.5 \%)$ were most frequent followed by dermatitis $(n=4,1.2 \%)$ 


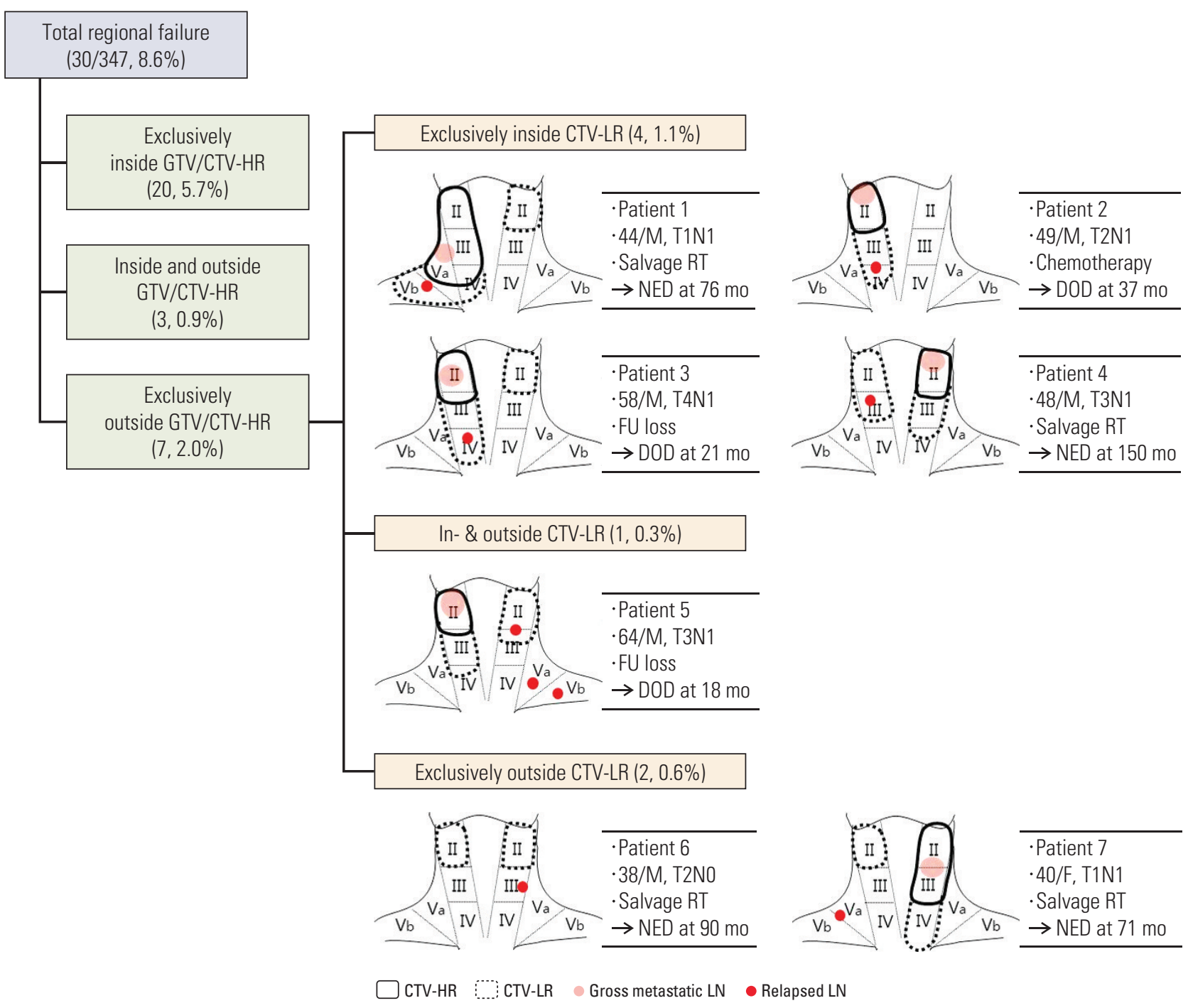

Fig. 3. The sites of regional failures in relation to target volume and detail of seven patients who developed regional failure in or outside clinical target volume at low risk (CTV-LR). GTV, gross tumor volume; CTV-HR, clinical target volume at high risk. RT, radiotherapy; NED, no evidence of disease; DOD, dead of disease; M, male.

and neutropenia $(\mathrm{n}=2,0.6 \%)$. Grade 3 or higher chronic toxicities included cranial neuropathy in 11 patients $(3.2 \%)$, mucosal necrosis in four $(1.2 \%)$, and brain necrosis in three $(0.9 \%)$, respectively. Grade 2 or higher xerostomia persisting longer than 3, 12, and 24 months following RT completion was observed in $38(11.0 \%), 23(6.6 \%)$, and 15 patients $(4.3 \%)$, respectively.

\section{Discussion}

Most previous clinical trials regarding NPC treatment advocated the routine bilateral entire neck irradiation from the retropharyngeal LNs to the level IV/V [9]. However, the rarity of skip metastasis in NPC and the improved LN assessment by advanced diagnostic imaging, coupled with the increased concern on post-RT quality of life, have promoted to the introduction of SNI. The feasibility of omitting level $\mathrm{Ib}$ or $\mathrm{IV} / \mathrm{Vb}$ from the lymphatic target volume is most frequently addressed in regards to SNI. One analysis on 1,438 NPC patients examined the safety of level Ib-sparing IMRT 
Table 2. Comparison of regional control rates and survival between the current study and other studies employing entire neck irradiation

\begin{tabular}{|c|c|c|c|c|}
\hline Study & No. of patients & Median FU (mo) & Regional control rate & Survival outcomes (\%) \\
\hline Wolden et al. (2006) [22] & 74 & 35 & $93 \%$ at $3 \mathrm{yr}$ & $\begin{array}{l}\text { OS } 83 \text { at } 3 \text { yr } \\
\text { DFS } 67 \text { at } 3 \text { yr }\end{array}$ \\
\hline Wong et al. (2010) [23] & 175 & 34 & $93.3 \%$ at $3 \mathrm{yr}$ & $\begin{array}{l}\text { OS } 87.2 \text { at } 3 \text { yr } \\
\text { DMFS } 86.6 \text { at } 3 \text { yr }\end{array}$ \\
\hline Wang et al. (2013) [24] & 300 & 80.2 & $95.1 \%$ at $4 \mathrm{yr}$ & $\begin{array}{l}\text { OS } 96.1 \text { at } 4 \mathrm{yr} \\
\text { DMFS } 87.4 \text { at } 4 \mathrm{yr}\end{array}$ \\
\hline Au et al. (2018) [25] & 3,328 & 80.2 & $91.5 \%$ at $8 \mathrm{yr}$ & $\begin{array}{l}\text { OS } 68.5 \text { at } 8 \text { yr } \\
\text { DFS } 62.6 \text { at } 8 \text { yr }\end{array}$ \\
\hline Current study & 347 & 68.1 & $92.6 \%$ at $3 \mathrm{yr}$ & $\begin{array}{l}\text { OS } 87.1 \text { at } 3 \mathrm{yr} \\
\text { DFS } 74.7 \text { at } 3 \mathrm{yr}\end{array}$ \\
\hline
\end{tabular}

FU, follow-up; OS, overall survival; DFS, disease-free survival; DMFS, distant metastasis-free survival.

[10], and reported only three recurrences at level $\mathrm{Ib}(0.2 \%)$. Chen et al. [11] evaluated the impact of omitting levels $\mathrm{IV} / \mathrm{Vb}$ in $212 \mathrm{cN} 0-1 \mathrm{NPC}$ patients and affirmed the effectiveness and safety of the SNI strategy. Gao et al. [12] also employed SNI limited to level II, III, and Va in treating 410 cN0 NPC patients, and observed only one relapse $(0.2 \%)$ outside this volume. On the basis of aforementioned evidence, the most up-to-date international guideline does not recommend the routine inclusion of ipsilateral level $\mathrm{Ib}$ and $\mathrm{IV} / \mathrm{Vb}$ to nodal CTV [13].

The current guidelines regarding the ENI volume delineation are based on the anatomic landmarks which include the hyoid bone, cricoid cartilage, posterior margin of the sternocleidomastoid muscle, and the line between shoulder and neck junction to medial clavicle end [13]. These anatomic landmarks are proposed mainly for surgeons' as they are easily identifiable to provide information during surgery, however, are less meaningful to radiation oncologists, as they are not relevant to the cancer cells' spread through the lymphatic channels. Instead of the surgical landmark-based LN levels, the current study employed lymphatic CTV delineation policy by adding differential margins from GTV of LN.

The ENI dose of 44-64 Gy to the clinically uninvolved lymphatics has usually been recommended in most head and neck cancer types [13]. However, there has been no clear guidance on the optimal ENI dose in treating the NPC patients. Fletcher [5] reported that 50 Gy could eradicate $95 \%$ of subclinical disease, whereas 30-40 Gy were associated with regional relapse in $9 \%-10.5 \%$. These recommendations were based on the data collected during the first generation CT era, when the image quality was suboptimal in detecting subclinical disease compared with the current standard. The tumor control probability (TCP) is, theoretically as well as practically, associated with the tumor burden and likelihood of occult disease, and so is the elective radiation dose to achieve effective tumor control $[14,15]$. Assuming that the probability of occult disease be $20 \%$, the radiation dose in order to achieve TCP of 95\% would be 40-50 Gy, if the occult disease tumor burden is equivalent to $10 \mathrm{~mm}$ sized gross tumor, and would become 35-40 Gy if the tumor burden is equivalent to 5-mm-sized gross tumor [16]. With the advances in diagnostic imaging modalities, detection of metastatic deposits in the LNs has become much easier than in the past, and the elective radiation dose also needs to be redefined accordingly. van den Bosch et al. [16] also suggested that elective dose of $36 \mathrm{~Gy}$ might be feasible theoretically with the current diagnostic strategies to achieve $95 \%$ of TCP. Moreover, favorable clinical outcomes were achievable following elective dose of $36 \mathrm{~Gy}$ in treating human papillomavirus (HPV)-related anal cancer [17], and there are emerging evidences supporting to deliver 36 Gy as elective dose in treating HPV-associated oropharyngeal cancer. These imply the feasibility of $36 \mathrm{~Gy}$ in treating nasopharyngeal cancer that is usually associated with Epstein-Barr virus infection.

In addition, there were several clinical studies that addressed the feasibility of lower ENI dose in treating head and neck cancer $[18,19]$. Bedi et al. [18] showed no difference in LRC in the patients who received lower than conventional ENI dose. Salama et al. [19] compared three different ENI dose schemes (45 Gy, 39 Gy, and 36 Gy) in treating the head and neck cancer patients, and found that LRC and OS were not different among the groups. A prospective trial [20], which compared elective doses of $40 \mathrm{~Gy}$ and $50 \mathrm{~Gy}$, demonstrated that lower ENI dose was not inferior with respects to LRC and OS. In the current study, seven among 30 patients (23.3\%) who developed regional recurrence had exclusively outside GTV / CTV-HR recurrence. Kong et al. [21] reported that, following bilateral whole neck irradiation except level 
IB with $54 \mathrm{~Gy}$, three of 11 patients (27.3\%) developed regional recurrence within the elective irradiation volume. Although fair comparison is impossible because of heterogeneity in tumor characteristics and RT dose schedules, the recurrence rates in the elective volume in the current study do not seem detrimental. Not only LRC and OS but also regional control rate of the current study ( $92.6 \%$ at 3 years) was not inferior, when compared to the previous studies that employed entire neck irradiation policy (Table 2).

One may raise an argument in that one should not take the risk of recurrence by reducing ENI volume and dose, as the RT toxicities may not be severe if IMRT is used. However, a recent study regarding the oral health quality of the head and neck cancer patients following IMRT reported that the salivary flow was recovered only by $40 \%$ and suggested that further reduced dose to the salivary glands is warranted [26]. Several retrospective studies revealed that reduced mean dose to the submandibular gland, oral cavity, and parotid gland is associated with diminished patient-reported xerostomia without increasing local recurrences $[27,28]$. Along with the advances in RT technique, lower elective dose can attribute to reduce toxicities by decreasing the irradiated dose of normal organs [16]. Two prospective studies reported lower ENI dose could prevent dysphagia and salivary dysfunction $[20,29]$. A recent phase II study also revealed that the lower elective dose of $36 \mathrm{~Gy}$ in head and neck cancer patients improved the patient-reported quality of life score and decreased the rate of percutaneous feeding gastrostomy tube insertion [30].

Despite the retrospective nature, the current study is the first one reporting the clinical outcomes following reduced ENI volume and lower ENI dose of 36 Gy in treating the NPC patients. The clinical outcomes of the current study could support the feasibility of authors' policy of SNI with lower elective dose in treating nasopharyngeal cancer. Thorough image evaluation and meticulous peer review in target delineation process are deemed integral points for the successful execution of the SNI policy. Larger prospective clinical trials, however, might be warranted to endorse our conclusions.

\section{Conflicts of Interest}

Conflict of interest relevant to this article was not reported.

\section{References}

1. Lee AW, Tung SY, Chua DT, Ngan RK, Chappell R, Tung R, et al. Randomized trial of radiotherapy plus concurrent-adjuvant chemotherapy vs radiotherapy alone for regionally advanced nasopharyngeal carcinoma. J Natl Cancer Inst. 2010;102:1188-98.

2. Ou SH, Zell JA, Ziogas A, Anton-Culver H. Epidemiology of nasopharyngeal carcinoma in the United States: improved survival of Chinese patients within the keratinizing squamous cell carcinoma histology. Ann Oncol. 2007;18:29-35.

3. Ho FC, Tham IW, Earnest A, Lee KM, Lu JJ. Patterns of regional lymph node metastasis of nasopharyngeal carcinoma: a meta-analysis of clinical evidence. BMC Cancer. 2012;12:98.

4. Lee AW, Sham JS, Poon YF, Ho JH. Treatment of stage I nasopharyngeal carcinoma: analysis of the patterns of relapse and the results of withholding elective neck irradiation. Int J Radiat Oncol Biol Phys. 1989;17:1183-90.

5. Fletcher GH. Elective irradiation of subclinical disease in cancers of the head and neck. Cancer. 1972;29:1450-4.

6. Edge SB, Byrd DR, Compton CC, Fritz AG, Greene FL, Trotti A. AJCC cancer staging handbook: from the AJCC cancer staging manual. New York: Springer; 2011.

7. Jeong Y, Baek S, Park JW, Joo JH, Kim JS, Lee SW. Lymph node standardized uptake values at pre-treatment (18)F-fluorodeoxyglucose positron emission tomography as a valuable prognostic factor for distant metastasis in nasopharyngeal carcinoma. Br J Radiol. 2017;90:20160239.
8. Hoang JK, Vanka J, Ludwig BJ, Glastonbury CM. Evaluation of cervical lymph nodes in head and neck cancer with CT and MRI: tips, traps, and a systematic approach. AJR Am J Roentgenol. 2013;200:W17-25.

9. Lee NY, Zhang Q, Pfister DG, Kim J, Garden AS, Mechalakos $\mathrm{J}$, et al. Addition of bevacizumab to standard chemoradiation for locoregionally advanced nasopharyngeal carcinoma (RTOG 0615): a phase 2 multi-institutional trial. Lancet Oncol. 2012;13:172-80.

10. Zhang F, Cheng YK, Li WF, Guo R, Chen L, Sun Y, et al. Investigation of the feasibility of elective irradiation to neck level $\mathrm{Ib}$ using intensity-modulated radiotherapy for patients with nasopharyngeal carcinoma: a retrospective analysis. BMC Cancer. 2015;15:709.

11. Chen JZ, Le QT, Han F, Lu LX, Huang SM, Lin CG, et al. Results of a phase 2 study examining the effects of omitting elective neck irradiation to nodal levels $\mathrm{IV}$ and $\mathrm{Vb}$ in patients with N(0-1) nasopharyngeal carcinoma. Int J Radiat Oncol Biol Phys. 2013;85:929-34.

12. Gao Y, Zhu G, Lu J, Ying H, Kong L, Wu Y, et al. Is elective irradiation to the lower neck necessary for $\mathrm{N} 0$ nasopharyngeal carcinoma? Int J Radiat Oncol Biol Phys. 2010;77:1397-402.

13. Lee AW, Ng WT, Pan JJ, Poh SS, Ahn YC, AlHussain H, et al. International guideline for the delineation of the clinical target volumes (CTV) for nasopharyngeal carcinoma. Radiother Oncol. 2018;126:25-36. 
14. Withers HR, Peters LJ, Taylor JM. Dose-response relationship for radiation therapy of subclinical disease. Int J Radiat Oncol Biol Phys. 1995;31:353-9.

15. van den Bosch S, Dijkema T, Verhoef LC, Zwijnenburg EM, Janssens GO, Kaanders JH. Patterns of recurrence in electively irradiated lymph node regions after definitive accelerated intensity modulated radiation therapy for head and neck squamous cell carcinoma. Int J Radiat Oncol Biol Phys. 2016; 94:766-74.

16. van den Bosch S, Vogel WV, Raaijmakers CP, Dijkema T, Terhaard $\mathrm{CHJ}$, Al-Mamgani A, et al. Implications of improved diagnostic imaging of small nodal metastases in head and neck cancer: radiotherapy target volume transformation and dose de-escalation. Radiother Oncol. 2018;128:472-8.

17. Gunderson LL, Winter KA, Ajani JA, Pedersen JE, Moughan J, Benson AB 3rd, et al. Long-term update of US GI intergroup RTOG 98-11 phase III trial for anal carcinoma: survival, relapse, and colostomy failure with concurrent chemoradiation involving fluorouracil/mitomycin versus fluorouracil / cisplatin. J Clin Oncol. 2012;30:4344-51.

18. Bedi M, Firat S, Semenenko VA, Schultz C, Tripp P, Byhardt $\mathrm{R}$, et al. Elective lymph node irradiation with intensity-modulated radiotherapy: is conventional dose fractionation necessary? Int J Radiat Oncol Biol Phys. 2012;83:e87-92.

19. Salama JK, Stenson KM, Kistner EO, Mittal BB, Argiris A, Witt $\mathrm{ME}$, et al. Induction chemotherapy and concurrent chemoradiotherapy for locoregionally advanced head and neck cancer: a multi-institutional phase II trial investigating three radiotherapy dose levels. Ann Oncol. 2008;19:1787-94.

20. Nevens D, Duprez F, Daisne JF, Dok R, Belmans A, Voordeckers $\mathrm{M}$, et al. Reduction of the dose of radiotherapy to the elective neck in head and neck squamous cell carcinoma; a randomized clinical trial. Effect on late toxicity and tumor control. Radiother Oncol. 2017;122:171-7.

21. Kong F, Ying H, Du C, Huang S, Zhou J, Chen J, et al. Patterns of local-regional failure after primary intensity modulated radiotherapy for nasopharyngeal carcinoma. Radiat Oncol. 2014;9:60.

22. Wolden SL, Chen WC, Pfister DG, Kraus DH, Berry SL, Zelefsky MJ. Intensity-modulated radiation therapy (IMRT) for nasopharynx cancer: update of the Memorial Sloan-Kettering experience. Int J Radiat Oncol Biol Phys. 2006;64:57-62.

23. Wong FC, Ng AW, Lee VH, Lui CM, Yuen KK, Sze WK, et al. Whole-field simultaneous integrated-boost intensity-modulated radiotherapy for patients with nasopharyngeal carcinoma. Int J Radiat Oncol Biol Phys. 2010;76:138-45.

24. Wang R, Wu F, Lu H, Wei B, Feng G, Li G, et al. Definitive intensity-modulated radiation therapy for nasopharyngeal carcinoma: long-term outcome of a multicenter prospective study. J Cancer Res Clin Oncol. 2013;139:139-45.

25. Au KH, Ngan RK, Ng AW, Poon DM, Ng WT, Yuen KT, et al. Treatment outcomes of nasopharyngeal carcinoma in modern era after intensity modulated radiotherapy (IMRT) in Hong Kong: a report of 3328 patients (HKNPCSG 1301 study). Oral Oncol. 2018;77:16-21.

26. Pow EH, Kwong DL, Sham JS, Lee VH, Ng SC. Can intensitymodulated radiotherapy preserve oral health-related quality of life of nasopharyngeal carcinoma patients? Int J Radiat Oncol Biol Phys. 2012;83:e213-21.

27. Yang H, Chen X, Lin S, Rong J, Yang M, Wen Q, et al. Treatment outcomes after reduction of the target volume of intensity-modulated radiotherapy following induction chemotherapy in patients with locoregionally advanced nasopharyngeal carcinoma: a prospective, multi-center, randomized clinical trial. Radiother Oncol. 2018;126:37-42.

28. Hawkins PG, Lee JY, Mao Y, Li P, Green M, Worden FP, et al. Sparing all salivary glands with IMRT for head and neck cancer: longitudinal study of patient-reported xerostomia and head-and-neck quality of life. Radiother Oncol. 2018;126:6874.

29. Nuyts S, Lambrecht M, Duprez F, Daisne JF, Van Gestel D, Van den Weyngaert D, et al. Reduction of the dose to the elective neck in head and neck squamous cell carcinoma, a randomized clinical trial using intensity modulated radiotherapy (IMRT): dosimetrical analysis and effect on acute toxicity. Radiother Oncol. 2013;109:323-9.

30. Maguire PD, Neal CR, Hardy SM, Schreiber AM. Single-arm phase 2 trial of elective nodal dose reduction for patients with locoregionally advanced squamous cell carcinoma of the head and neck. Int J Radiat Oncol Biol Phys. 2018;100:1210-6. 